\title{
Caminhos para um Outro Jornalismo: Do Discurso à Situação Comunicativa da "Boa Enunciação"1
}

\author{
Guilherme LUCIAN ${ }^{2}$ \\ Ângela Teixeira de MORAES ${ }^{3}$ \\ Universidade Federal de Goiás, Goiânia, GO
}

\section{RESUMO}

Neste trabalho são propostos, a partir de uma discussão teórica, caminhos à compreensão da atividade jornalística vista sob a ótica da "enunciação positiva" - cujo conceito será inicialmente explorado para então esclarecer seu tangenciamento em relação à pretensão de reforçar no discurso do jornalismo atitudes mais humanas e vinculativas. A noção de formação discursiva será posta em relevo para observar sob quais condições esse tipo de enunciação legitima seu saber, e por fim também apresentadas direções aos (re)arranjos deontológicos do jornalismo. Espera-se, com isso, evidenciar estratégias epistemológicas criativas ao estudo deste campo na área da Comunicação.

PALAVRAS-CHAVE: comunicação; discurso; jornalismo.

\section{A CONFIGURAÇÃO DO JORNALISMO}

Nos últimos anos, despontou à luz um tipo singular de jornalismo, o qual, em vez de se orientar por estratégias mercadológicas específicas - muitas das quais, inclusive, são características do exercício -, esforça-se à construção de uma situação comunicativa racional com o público. Trata-se, portanto, de um “jornalismo positivo”, cuja enunciação tangencia uma trajetória discursiva marcada pela solidariedade, pelo "sentir-se bem" e pela urgência de assegurar pontes comunicantes entre universos simbólicos destoantes.

Parte-se aqui de uma noção de comunicação ancorada - ao menos em termos epistemológicos - no racionalismo crítico, tendo-se então como parâmetro um horizonte normativo futuro. A palavra norma, neste trabalho, não remete a um imperativo, mas sim à busca por um ideal que é, conforme ao fim exercida a atividade jornalística, sustentado como necessário. Noutros termos, situa-se o fenômeno comunicacional em relação à ideia

\footnotetext{
${ }^{1}$ Trabalho apresentado na DT 1 - Jornalismo do XXI Congresso de Ciências da Comunicação na Região Centro-Oeste, realizado de 22 a 24 de maio de 2019.

2 Doutorando do Curso de Comunicação da FIC-UFG, e-mail: guilherme.lucian@gmail.com

${ }^{3}$ Orientadora do trabalho. Professora do Curso de Jornalismo da FIC-UFG, e-mail: prof.atmoraes@ gmail.com
} 
de racionalidade (semelhante ao que, em seus esforços teóricos, propõe Habermas ${ }^{4}$ ), para daí então observar como a questão de uma enunciação positiva opera no jornalismo.

Estudar a atividade jornalística é, por um lado, ter em vista o esforço singular despendido à organização das conversas sociais de uma época. Tal processo - articulado segundo dinâmicas particulares e combinações deontológicas singulares - arquiteta seu sistema de narrativa para então evidenciar as experiências aleatórias da vida.

A organização jornalística, sustentada por critérios específicos de captação e (re)trabalho discursivo (os quais evidenciam o que há de mais imediato na atualidade) se constitui a partir de uma ação duplamente orientada: tende a ser referência tanto à maneira como são narrados os eventos sociais, como também à possibilidade de servir enquanto espaço de partilha para que a sociedade fale de si - conforme então enunciadas as notícias que, em maior ou menor grau, asseguram coerência às disposições recentes de histórias vividas.

A discursividade social da enunciação jornalística busca critérios legitimadores de relevância pública - tanto menos por credibilidade, mas pela urgência de repercussão no cotidiano. Relevância, contudo, não é necessariamente atributo ao acontecimento; é, pelo contrário, atribuída em função de contextos sócio-históricos próprios à discursividade da notícia. Não por acaso, pois, o jornalismo opera "dentro das fronteiras do que é admitido socialmente" (CORREIA, 2009, p. 172), vinculando-se assim às percepções mais óbvias do que pode ser então considerado relevante.

O exercício jornalístico de referência - este que, de modo geral, padroniza ações enunciativas - parece seguir caminho contrário àquele proposto por práticas discursivas alternativas; isto porque as singularidades de sua institucionalização por vezes escapam à orientação deontológica (e idealizada) do jornalismo. Seja pela busca de uma ancoragem capitalista, ou por desconsiderar a dimensão comunicativa pressuposta na trajetória sóciohistórica de sua narrativa.

O imperativo de atribuir relevância temática aos acontecimentos surgidos de experiências e diálogos sociais dispersos é, portanto, parte do que configura a organização discursiva do jornalismo - conforme então torna compreensíveis as histórias noticiadas, tendo por princípio um conjunto de saberes e dinâmicas particulares. É possível, porém, situar sua deontologia para além da regularidade enunciativa hegemônica, na medida em

\footnotetext{
${ }^{4}$ Cf. HABERMAS (1999; 2012).
} 
que, de circuito, são afinal tiradas as urgências comerciais para tangenciar uma certa sintonia responsável em relação ao compromisso com a sociedade.

Caminhos, nesse sentido, são traçados há algum tempo por jornalistas que tentam situar o compromisso de sua profissão em relação à construção de uma discursividade alternativa - embora menos plural, considerando-se aqui a limitação enunciativa sob a égide dum só aspecto, qual seja: o positivo. Espécie de terceira via, pois, a qual evidencia (de modo arriscado, por certo) escolhas editoriais não necessariamente associadas à vigilância do Estado ou mesmo às exigências mercadológicas, solicitando a atuação de movimentos sociais organizados a partir de ações não-governamentais. Cita-se aqui, como exemplo mais explícito, os websites independentes mantidos por jornalistas que em alguns casos se voluntariam para (re)organizar as regras e estratégias ideológicas de um discurso que assegure passagens seguras entre o ato meramente informativo e o vínculo duradouro com o cidadão.

São assim desenhadas, pois, possibilidades alternativas à configuração discursiva da profissão. À medida então que os jornalistas - em seu esforço de compor a trama das narrativas históricas - parecem pôr entre parênteses os desvios da própria deontologia; estes que, por razões instrumentais, rompem com a idealização normativa esperada.

Por muito - devido à sua trajetória histórica -, considerou-se haver no jornalismo um primado ancorado na objetividade, sobretudo quando situado em relação à construção dos quadros de referência à opinião pública (MELO, 2012). Configurações recentes em seu sistema narrativo, porém, sugerem a formação doutro discurso - mais sensível, aliás; orientado por direções contrárias às das práticas que institucionalizam sua noticiabilidade. Um exercício de tipo aberto, portanto, o qual permite repensar enunciações e assim servir para impulsionar mudanças positivas na realidade social ${ }^{5}$.

Tendo-se em conta tais mudanças, evidencia-se então uma trajetória jornalística singular, qual seja: a da discursividade orientada segundo os parâmetros da "boa notícia", cujo propósito, ao menos o mais aparente, é distanciar-se das referenciações enunciativas já estabelecidas na profissão para propor ações que efetivamente transformem o discurso de uma época e resgatem uma racionalidade comunicativa. Eis como a questão de um

\footnotetext{
${ }^{5}$ Uma pesquisa conduzida em 2014 pelo Center for Media Engagement, da Universidade do Texas em Austin, mostra que os textos jornalísticos que enunciavam acontecimentos considerados "ruins" (os quais também apresentavam soluções possíveis aos problemas abordados) estimulavam no público um sentimento positivo de otimismo, a ponto de solicita-lo a querer se engajar na vida cívica. Os resultados desse estudo podem ser conferidos no sítio: https://mediaengagement.org/research/solutions-journalism/.
} 
$\overline{\text { saber positivo (ou construtivo, conforme o vocabulário tomado por apoio) se estendeu ao }}$ campo da Comunicação para descrever um deslizamento teórico do que, antes, situou-se no domínio epistemológico da Psicologia 6 .

O conceito de positividade - ainda incipiente no que diz respeito a uma teorização consistente - pode evidenciar os tipos de conhecimento que sustentam um saber sensível ao jornalismo, promovendo assim, à guisa de intervenções cognitivo-comportamentais, a passagem segura do ato de narrar a realidade à vontade de solicitar o público a ações humanas e vinculativas. Vincular-se, no escopo analítico deste trabalho, é "uma exigência radical de partilha da existência com o Outro" (SODRÉ, 2006, p. 93), quando então admitidas as dificuldades ontológicas que estorvam a coabitação ${ }^{7}$; ou mesmo, em termos habermasianos, quando buscada uma ética discursiva capaz de assegurar condições racionais à compreensão mútua (HABERMAS, 2012) .

Ao ancorar a comunicação na racionalidade - opondo-se assim a outro tipo de razão, qual seja: a teleológica -, Habermas busca alcançar uma situação ideal de fala, na qual, ao acionar pretensões que sejam válidas a todos os partícipes no contexto de uma racionalidade discursiva, chega-se afinal ao entendimento. É nesse ponto que, enquanto pretensão de validade orientadora de uma situação comunicativa racional, a positividade passa ao largo da ação estratégica por vezes comum ao exercício jornalístico; sobretudo quando orientado segundo a contramão de sua normatividade. Não se trata, contudo, de situar a análise comunicativa no espaço do jornalismo em termos semelhantes aos de uma teorização religiosa (por assim dizer) - isto é, evidenciando-se o mal para enfim tratar do bem -, mas, pelo contrário, submeter conscientemente à crítica a instrumentalização da enunciação negativa para daí sim compreender os desvios em relação à sua deontologia (esta que, ao menos em termos normativos, não destoa em muito da proposta positiva).

Para esclarecer tais (re)arranjos, todavia, é necessário que sejam antes exploradas as fronteiras teóricas que articulam a ética jornalística a uma formação discursiva positiva.

\footnotetext{
${ }^{6}$ Cf., por exemplo, KEYES e HAIDT (2003); e GYLDENSTED (2011).

${ }^{7}$ A este respeito, para estudo aprofundado, cf. WOLTON (1997; 2000), (HABERMAS, 1999, 2012) e SODRÉ (2006; 2014).

${ }^{8}$ Aqui, contudo, o horizonte conceitual não versa sobre as regras orientadoras dessa ação (as quais operam, segundo Habermas, por um entendimento consensual). $\mathrm{O}$ intuito é trazer à luz a discursividade desse esforço comunicativo no jornalismo para então responder à questão posta como primado: quem é, para mim, esse Outro com o qual me comunico, e junto ao qual, portanto, permito-me à aventura complicada de nossas diferentes realidades?
} 


\section{A ANCORAGEM CONCEITUAL DA POSITIVIDADE}

Presume-se, ao ter como horizonte a enunciação positiva, uma responsabilidade epistemológica na ação do analista - conforme são consideradas, ao tomar de empréstimo um núcleo conceitual da Psicologia (o qual emerge e varia como atributo valorativo), cada aplicação teórica possível no campo da Comunicação. Não menos responsável, pois, o entendimento da organização sistemática de conversas sociais para além de sua dimensão mais óbvia, qual seja: a formação de uma narrativa preferencial (ou conservadora) que reduz a complexidade das múltiplas vozes engajadas na discursividade jornalística.

Para situar a positividade em relação às problemáticas teóricas da Comunicação, deve-se também ter em conta as implicações éticas e deontológicas postas em relevo na trajetória do discurso jornalístico - seja para considerar suas fronteiras, ou no que pese ter clareza quanto aos movimentos da palavra em ato. Buscar, afinal, efeitos de sentido que se cruzam, afastam-se e caracterizam um jornalismo não mais pensado apenas sob a égide de princípios funcionais - muitos dos quais, inclusive, confundidos com a própria dinâmica de suas estratégias -, mas que se ergue então como uma espécie de "força para o bem" (STREITMATTER, 2015).

As bases teóricas da positividade são ainda precárias, naturalmente - sobretudo quando analisada segundo a lógica de uma discursividade própria ao jornalismo. É possível entendê-la, porém, a partir de três temas-chaves, os quais, segundo Seligman (2012, p. 37), consistem em: emoção positiva, vínculo e sentido ${ }^{9}$, na medida em que a palavra "positivo", além de operar em função desses direcionamentos, pode também servir para convocar sujeitos à vontade de solucionar problemas e conflitos sociais.

O que captura ${ }^{10}$ o público pela emoção que "faz bem”, que lhe solicita a engajarse, construir um vínculo de algum modo afetivo; que lhe apanhe em sentidos e que desperte um senso de que nesse processo algo "bom" foi realizado é, portanto, parte do que pode conduzir a uma reflexão e experiência explícitas em torno do entendimento da positividade em seu horizonte de contextualização teórica na Comunicação.

\footnotetext{
${ }^{9}$ No texto original: positive emotion, engagement, and meanings. Os termos "engagement" e "meaning" foram aqui adaptados como vínculo e sentido, respectivamente, em vez de "engajamento" e "significado". Essa escolha caracteriza a conceituação feita pelo autor a respeito de uma teoria da felicidade autêntica, além de se ajustar melhor quando são tomados de empréstimo da Psicologia alguns pressupostos teóricos que no campo da Comunicação seguiram outras trajetórias epistemológicas.

${ }^{10}$ Capturar é assumir a configuração de dispositivo, o qual orienta, intercepta e assegura um discurso. Cf. AGAMBEN, G. O que é um dispositivo? In: AGAMBEN, G. O que é o contemporâneo? E outros ensaios. Chapecó, SC: Argos, 2009. Cap. 1, p. 25-51.
} 
Pensar a prática jornalística nesses termos, portanto, é considera-la tendo-se em vista os seguintes caminhos: a) o que há de servir ao exercício de enunciação que se institucionaliza como parte responsável da configuração social de uma época (à medida que convoca o público a participar de seu sistema narrativo) -; b) e o que pode indicar as estratégias de uma razão sensível para se contrapor ao próprio discurso do jornalismo - historicamente situado como factual, insólito e por vezes até deprimente (MORAES, 2014), operando então a partir de uma coesão moral orientada a aspectos normativos da vida humana.

De modo similar à ambiguidade teórica na formação conceitual da positividade visto que estão aí pressupostos valores que dependem de operações subjetivas -, também não é possível extrair com máxima exatidão o núcleo epistemológico que caracteriza um “jornalismo positivo", porque isso dependeria da referência adotada ou mesmo da clareza quanto à distância entre o ideal normativo e a realidade discursiva para então compreender os limites do acontecimento noticiável e seus procedimentos éticos.

Inferir que uma notícia é "boa" pode significar que ela foi melhor do que a média enunciada, o que equivale a afirmar que ela cumpriu certos padrões em grau superior à maioria das demais notícias - tal que, nesse caso, a palavra "boa" é usada como um termo hierarquizador. Ou, pode-se superar a classe de comparação para se chegar àquela dos possíveis e imagináveis, o que, enquanto termo qualificativo, equivale a afirmar que uma notícia é "boa" quando são cumpridos os padrões que definem uma enunciação ideal. E não menos importante, esse "bom" pode também se referir a uma pretensão de validade, conforme o exercício do jornalismo sustenta a necessidade de submeter a críticas suas proposições normativas e seus procedimentos deontológicos.

Por isso não há um rumo direto de inferência, e toda certeza deve antes considerar o sujeito em seu papel a desempenhar, qual seja: discernir e valorar o que é uma notícia que lhe faz bem. É nesse ponto que a positividade não se articula estritamente a uma denotação inflexível, porque seu efeito de sentido ${ }^{11}$ é configurado tendo-se por base uma rede de cenas enunciativas particulares; ele próprio a funcionar como vontade de verdade, isto é, um saber que exerce sobre outros um poder de pressão, conduzindo então o modo

\footnotetext{
${ }^{11}$ A trajetória da palavra não apenas tem sentido, como também é sentida. Não se restringe, pois, à transmissão de algo já dado, mas sim à construção de uma dimensão sensível em ato de troca (MAINGUENEAU, 1996).
} 
como "é operado em uma sociedade, como é valorizado, distribuído, repartido e de certo modo atribuído" (FOUCAULT, 2001, p. 16) ${ }^{12}$.

A questão do "fazer bem", enquanto valor atribuído ao ato enunciativo, sugere então outro parâmetro de referência aos sujeitos - conforme lhes fornece modelos de comportamento e hábitos institucionalizados a partir de um saber que parece fazer frente à imposição hegemônica da atividade. Seja pela busca de um novo acordo com o leitor, pois, ou por tentar (re)ajustar discursos que foram antes classificados como perturbadores, violentos, e degradantes ${ }^{13}$.

Eis a hipótese, afinal: ao orientar-se por um discurso positivo, o jornalismo busca alcançar três atitudes essenciais: a) informar de maneira responsável o acontecimento que pode mobilizar o leitor a querer refletir, participar e intervir na construção de um sistema de narrativa cujas regras de funcionamento permitem questionar a validade da própria atividade jornalística; b) legitimar a pretensão de enunciar somente o que se mostre socialmente útil à composição de um quadro de referência a ações transformadoras da realidade (resgatando assim a dimensão normativa da comunicação, isto é, seu horizonte humano de abertura às realidades do Outro ${ }^{14}$ ); c) reforçar a positividade para convocar jornalista e público à vontade de promover, no plano da cidadania, resistências ao discurso midiático dominante.

Os efeitos de sentido em torno de um discurso orientado à "boa notícia”, portanto, devem conduzir à clareza crítica de suas trajetórias e condições de produção - seja para analisar os contextos ideológicos que tangenciam escolhas temáticas (ORLANDI, 2009), princípios e situações comunicativas regulares ou discrepantes, como para investigar até que ponto a ênfase editorial da "boa enunciação" pode servir aos padrões conceituais de noticiabilidade sem limitar a própria narrativa jornalística ou impedir a configuração de espaços por onde circulem suas tantas contradições e perspectivas de mundo.

É preciso então, tendo-se por horizonte tais caminhos, caracterizar transformações e efeitos de sentido que destaquem um eixo epistemológico no qual estejam devidamente situados os saberes do discurso positivo em relação à sua historicidade.

\footnotetext{
12 Tradução livre, a partir do trecho: "par la manière don’t le savoir est mis en œuvre dans une société, dont il est valorisé, distribué, réparti et en quelque sorte attribué." As demais citações das obras de Foucault seguem, neste trabalho, o mesmo critério e padrão.

${ }^{13}$ A este respeito, a empresa Google anunciou, em agosto de 2018, o recurso "Tell me Something Good" ("Diga-me algo positivo", em tradução livre), o qual, pelo comando de voz do Google Assistente, visa gerar boas notícias e estimular nos leitores uma postura de busca por soluções às questões cotidianas e de combate à violência.

${ }^{14}$ Cf. Wolton (2006), para quem comunicar é enxergar a dimensão do Outro como diferença sensível e motivadora.
} 


\section{PRINCÍPIOS À FORMAÇÃO DISCURSIVA POSITIVA}

Para mobilizar no estudo do jornalismo o conceito de positividade, deve-se antes analisar a característica da formação discursiva aí pressuposta - isto é, o feixe dinâmico de interações" (FOUCAULT, ROUANET, et al., 1996, p. 107) que traz à superfície os vestígios singulares sustentados pela tessitura ideológica do enunciado em ato -, como forma de caracterizar então a gênese, a variação e a continuidade dos tipos de palavra que servem como fundamento à composição de um saber específico (o qual poderia acontecer doutro modo, certamente, mas que se tornou o que é nos traços dessa sua trajetória).

Evidencia-se pela Análise de Discurso (AD), portanto, o saber que emerge de um texto em sua própria discursividade para observar as múltiplas ramificações semânticas seja em suas divergências como também nas justaposições assumidas. É, de modo geral, um ensaio particular, qual seja: tangenciar as singularidades da enunciação; sua relação com o passado ao futuro eventual possível.

Toda enunciação, para Foucault (1969), é um acontecimento que não se repete por isso a singularidade -, o qual deixa passar

um certo número de constantes: gramaticais, semânticas, lógicas, pelas quais se pode, neutralizando o momento da enunciação e as coordenadas que o individualizam, reconhecer a forma geral de uma frase, de uma significação, de uma proposição (p. 134). ${ }^{15}$

Descrever um enunciado é - tendo-se em conta a tese foucaultiana -, esforçar-se para definir suas condições de existência materializadas em uma posição ideológica e conjuntura sócio-histórica dadas, determinando assim o que pode e deve ser dito. É nesse ponto, pois, que a enunciação produz efeitos de sentido para relacionar um conjunto de signos a um certo domínio de objetos (MAINGUENEAU, 1997, p. 50), os quais emergem da regularidade ou discrepância apresentadas para integrar os saberes em sua relação entre texto, sujeito, conjuntura e história.

A materialidade repetível dos enunciados é estabelecida a partir de um a priori histórico, o qual opera como episteme - isto é, o solo originário que torna possível um conhecimento em seu conjunto de relações pelo qual se conectam os discursos de uma

\footnotetext{
${ }^{15}$ No original: "Cette singularité pourtant laisse passer un certain nombre de constantes : grammaticales, sémantiques, logiques, par lesquelles on peut, en neutralisant le moment de l'énonciation et les coordonnées qui l'individualisent, reconnaître la forme générale d'une frase, d'une signification, d'une proposition."
} 
época, assegurando assim os dizeres possíveis em uma formação discursiva. Esse feixe convergente de configurações do saber, portanto, é o que legitima socialmente a trajetória dos enunciados e captura os sujeitos à adesão de suas regras. Não se trata, porém,

de neutralizar o discurso, torna-lo signo de outra coisa e atravessar-lhe a espessura para alcançar o que permanece silenciosamente aquém dele, mas, pelo contrário, trata-se de mantê-lo em sua consistência, fazê-lo surgir na complexidade que lhe é própria (FOUCAULT, 1969, p. 65) ${ }^{16}$,

para então tangenciar indícios e tessituras possíveis. Sendo assim, o traço que torna noticiáveis os elementos enunciativos do discurso jornalístico é a possibilidade de interpretar o que foi dito (e o que permanece implícito no que se diz) a partir de um enquadramento sociocultural familiar. Assumindo-se então como veiculadores de "boas notícias", os jornais difundem um sistema de valoração, correspondente a uma ideologia e discurso específicos - historicizados e atravessados por outros discursos -, operando pela procura ativa por vínculos comunicativos duradouros; sustentada como necessária. Resta afinal saber se, pela configuração do a priori histórico, o valor positivo emerge quando então exauridos os cursos de uma negatividade subsumida na enunciação.

Para evidenciar o tangenciamento que libera a positividade ao conhecimento - isto é, o curso que a torna pensável, e que, sem inícios ou fins delineados, faz aparecer os efeitos de sentido pretendidos pela $\mathrm{AD}$-, busca-se nos vestígios sócio-históricos o saber que orienta a ação jornalística. Tal saber, carece explicitar, opera como uma forma nova de percepção e expressão (sensibilidade de mundo), na medida em que caracteriza o discurso positivo em seu jogo de (in)compatibilidades conceituais e em seu "sistema de relações materiais que o estrutura e constitui" (FOUCAULT, ROUANET, et al., 1996, p. $51)^{17}$.

Trata-se, pois, de ressaltar as condições de produção que designam o discurso de um “jornalismo positivo" - orientado à criação de arquiteturas sociais vinculativas específicas $^{18}$-, caracterizadas afinal por regras de um saber que se materializa na história.

\footnotetext{
${ }^{16}$ No original: "Mais ce don't il s'agit ici, ce n'est pas de neutralizer le discours, d'en faire le signe d'autre chose et d'en traveser l'épaisseur pour rejoindre ce qui demeure silencieusement en deçá de lui, c'est au contraire de le maintenir dans sa consistance, de le faire surgir dans la complexité qui lui est prope."

${ }^{17}$ Cf. LECOURT, D. A arqueologia e o saber. In: FOUCAULT, M., et al. O homem e o discurso: a arqueologia de Michel Foucault. Rio de Janeiro, RJ: Tempo Brasileiro, 1996. Cap. 2, p. 43-66.

18 Específicas porque, de modo geral, há também um vínculo pressuposto quando o público toma por parâmetro a enunciação não positiva.
} 
Deve-se também situar a análise discursiva em relação ao esforço epistemológico para tentar compreender como esse conhecimento opera no sentido de palavra de verdade, e então desvelar as características da formação discursiva que tangencia a questão de um saber positivo em sua tessitura especificamente comunicacional. Trazer à luz, afinal, o que há de regular ou singular na enunciação de um tipo de notícia em que os valores de uso segundo os quais orientam seu processo produtivo - isto é, os intercâmbios entre o ser social e a própria natureza discursiva do jornalismo - parecem sugerir um (re)arranjo que resiste aos desvios das deontologias consensuais da atividade.

Ancorar o jornalismo positivo na resistência - condição, portanto, de possibilidade à superação das relações assimétricas - é também pôr em relevo a questão de saber em que medida será possível romper com os mecanismos de classificação e identificação comuns ao exercício da profissão, articulando-o então a um enquadramento cuja ordem discursiva não toma por parâmetro apenas as enunciações tradicionais da violência e do desamparo (LEVINE, 1977); mas que contemple, na pretensão válida de reforçar ações vinculativas, valores que se mostrem socialmente úteis à vida cívica.

A positividade enquanto pretensão comunicativa - mais que um valor de noticiabilidade como outro qualquer - pode tangenciar o ideal normativo inscrito na narrativa jornalística, o qual aponta à urgência de assegurar (para então manter) passagens seguras entre universos simbólicos diferentes (WOLTON, 2006, p. 138). Eis como a enunciação positiva (mesmo em suas limitações) evidencia a dificuldade ontológica como fundamento à compreensão mútua; espécie de incomunicação (Ibid.), ou vazio gerativo (SODRÉ, 2014), que nos convoca a seguir com sensibilidade consciente à realidade do Outro.

Tal vazio - semelhante ao modo como na matemática opera o número zero em sua natureza de ausência criadora (SODRÉ, 2014, p. 215) -, solicita-nos a refletir sobre o que passa desapercebido no vínculo social; o comum como princípio de coerência (Ibid.) do que não se vê e que nos escapa às vistas (tangenciando assim o que antes não estava aí). Trata-se, pois, de uma reorientação racional à construção de pontes comunicantes entre diferenças, a qual explicita o horizonte intersubjetivo da comunicação no esforço mesmo da atividade jornalística. 
A dificuldade ontológica - posta à sensibilidade fundamenta $1{ }^{19}$ dos que mobilizam discursos em suas situações comunicativas - exige então esforço, luta perene, pois ao admitirmos os estorvos à intercompreensão, situamo-nos em relação à dimensão do Outro; este que, portanto, convoca-nos a ter-lhe alguma estima para então reconhece-lo enquanto sujeito. Eis como a positividade, no limite da sua pretensão, há de resgatar a perspectiva humana da comunicação (situada fora da urgência informativa e instrumental comum ao jornalismo).

Espera-se que, à construção de uma arquitetura vinculativa na esfera da cidadania, a trajetória discursiva até aqui delineada tangencie a positividade ao nível dos processos sócio-histórico-comunicativos, destacando então estratégias sensíveis (porém não menos inteligíveis ou mais racionais) para situarmos em relação ao exercício jornalístico um senso de comunidade aí pressuposto. Exige-se também da conotação dada à "boa notícia", pois, a seguinte orientação: entendê-la tendo-se em vista as características mais ou menos aparentes dos fatos noticiáveis e os processos regulatórios de uma ética aplicável ao conjunto de enunciações dirigidas à sociedade.

Qualquer caminho com fins ao rearranjo do jornalismo, afinal, convoca-nos uma atitude reflexiva. Daí a necessidade de mobilizar um esforço arqueológico no espaço de enunciação jornalística a fim de

individualizar o que seria a coexistência desses enunciados dispersos e heterogêneos; o sistema que rege sua repartição, como se apoiam uns nos outros, a maneira pela qual estão implicados ou se excluem, a transformação que sofrem, o jogo de seu revezamento, de sua disposição e de sua substituição (FOUCAULT, 1969, p. 48) ${ }^{20}$,

para então reagrupa-los, descrever encadeamentos e explicar como se apresentam em sua singularidade ou regularidade temáticas. Um esforço, pois, que concilie as experiências discursivas do "jornalismo positivo" não somente em relação à orientação normativa e racional da comunicação, mas também à vontade de querer participar da (re)organização das narrativas sociais de uma época.

\footnotetext{
${ }^{19}$ Porque criadora e porque situada como primado à racionalização assumida entre Eu e Outro, válida então para ambos em contextos especificamente comunicativos.

${ }^{20}$ No original: "Ce qu'il faudrait caractériser et individualiser ce serait la coexistence de ces énoncés dispersés et hétérogènes ; le système qui régit leur répartition, l'appui qu'ils prennent les uns sur les autres, la manière dont ils s'impliquent ou s'excluent, la transformation qu'ils subissent, le jeu de leur relève, de leur disposition et de leur remplacement."
} 


\section{ALGUMAS CONSIDERAÇÕES}

Feitas as devidas explanações, resta então perscrutar em que medida a positividade se institucionaliza enquanto discurso não conservador no jornalismo - tendo-se aqui em conta a pretensão de se mostrar como um tipo novo de olhar. E, não menos pertinente, compreender quais os tipos de pacto a enunciação positiva cria e mantém com o leitor, sobretudo no que diz respeito à maneira como os jornais tentam reajustá-la racionalmente para pôr em curso seus saberes.

Uma questão, porém, permanece evidente: é perigoso, por assim dizer, reduzir a enunciação jornalística às características de um sistema preferencial de narrativa, pois sua discursividade deve cruzar as fronteiras de uma razão sensível articulada à habitação (e experimentação) da realidade. É nesse ponto que o ideal normativo visto aqui sob rasura deve mobilizar jornalistas e leitores a uma sensibilidade inédita; espécie de pensamentovida que traga à luz soluções possíveis aos problemas sociais - mesmo nas enunciações caracterizadas como "infelizes", "trágicas" e "desalentadoras".

Trata-se, afinal, da mudança de uma episteme; esta que, fundamentalmente, serve como solo - nem sempre seguro ou estável - à dimensão historicizada da discursividade jornalística (inclusos aqui sua [i]mobilidade e encadeamento segundo a lógica da trajetória que lhe é concernente). O curso da "boa notícia", pois, pode conduzir não apenas à tendência de um jornalismo deontologicamente solidário, mas também à força sóciohistórica que assegura sua condição de existência e aceitação. Se acaso então houver irrelevância no modo como o próprio jornalismo organiza sua narrativa, a história em ato o substituirá por outras formas de vínculo com a realidade social. 


\section{REFERÊNCIAS}

AGAMBEN, G. O que é um dispositivo? In: AGAMBEN, G. O que é o contemporâneo? E outros ensaios. Chapecó, SC: Argos, 2009. Cap. 1, p. 25-51.

CORREIA, J. C. Teoria crítica do discurso noticioso: notas sobre jornalismo e representações sociais. Covilhã, Portugal: Livros LabCom - Universidade da Beira Interior, 2009.

FOUCAULT, M. L’archéologie du savoir. Paris: Éditions Gallimard, 1969.

, M. L'ordre du discours. Edition basée sur le texte proposé par l'édition CD-ROM, Le Foucault Électronique. ed. Paris: Éditions Gallimard, 2001.

, M. et al. (Eds.). O homem e o discurso: a arqueologia de Michel Foucault. 2. ed. Rio de Janeiro, RJ: Tempo Brasileiro, 1996.

GYLDENSTED, C. Scholarly Commons - Innovating News Journalism through Positive, 21 Nov. 2011. Disponivel em:

<https://repository.upenn.edu/mapp_capstone/20/?utm_source=repository.upenn.edu\%2Fmapp capstone\%2F20\&utm_medium=PDF\&utm_campaign=PDFCoverPages $>$. Acesso em: 3 fev. 2019.

HABERMAS, J. La inclusión del otro: estudios de teoría política. Barcelona: Paidós, 1999.

, J. Teoria do agir comunicativo: racionalidade da ação e racionalização social. 1. ed. São Paulo: Editora WMF Martins Fontes, v. 1, 2012.

J. Teoria do agir comunicativo: sobre a crítica da razão funcionalista. 1. ed. São Paulo: Editora WMF Martins Fontes, v. 2, 2012.

KEYES, C. L. M.; HAIDT, J. (Eds.). Flourishing: positive psychology and the life well-lived. Washington, DC.: American Psychological Association, 2003.

LEVINE, G. F. Learned Helplessness and the evening news. Journal of Communication, London, UK, dezembro 1977. 100-105.

MAINGUENEAU, D. Novas tendências em análise do discurso. 3. ed. Campinas, São Paulo: Pontes, 1997.

MELO, J. M. D. História do jornalismo: itinerário crítico, mosaico contextual. 1. ed. São Paulo: Paulus, 2012.

MORAES, Â. T. D. A positividade como valor-notícia: análise discursiva de webjornais orientados à "boa notícia". XXXVII Congresso Brasileiro de Ciências da Comunicação. Foz do Iguaçu, PR: [s.n.]. 2014. p. 12.

ORLANDI, E. P. Análise de discurso: princípios e procedimentos. 8. ed. Campinas, SP: Pontes, 2009.

SELIGMAN, M. E. P. Flourish: a visionary new understanding of happiness and wellbeing. 1. ed. New York, NY: Free Press, 2012. 
SODRÉ, M. As estratégias sensíveis: afeto, mídia e política. Petrópolis: Vozes, 2006. 2014.

M. A ciência do comum: notas para o método comunicacional. Petrópolis, RJ: Vozes,

STREITMATTER, R. force for good: how the american news have propelled positive change. 1. ed. London, UK: Rowman \& Littlefield, 2015.

WOLTON, D. Penser la communication. Paris: Flammarion, 1997.

D. Internet, et après ? Paris: Flammarion, 2000.

D. É preciso salvar a comunicação. São Paulo, SP: Paulus, 2006. 